$\$$ Research Square

\title{
Smoking and Dementia Status Among Older Americans: A Mendelian Randomization Analysis
}

\author{
Mingzhou Fu \\ University of Michigan \\ Jessica D. Faul \\ University of Michigan \\ Yuan Jin \\ University of Michigan \\ Erin B. Ware \\ University of Michigan \\ Kelly M. Bakulski ( $\square$ bakulski@umich.edu ) \\ University of Michigan
}

\section{Research Article}

Keywords: Smoking, polygenic score, dementia, cognitive impairment, epidemiology, Mendelian randomization

Posted Date: May 11th, 2021

DOI: https://doi.org/10.21203/rs.3.rs-496150/v1

License: (c) (i) This work is licensed under a Creative Commons Attribution 4.0 International License. Read Full License 


\section{Abstract}

Smoking is associated with dementia, but causality has not been well-established. Given smoking has a strong genetic component, we used genetic predisposition to smoking, based on a genome-wide association study (GWAS) from the GWAS \& Sequencing Consortium of Alcohol and Nicotine use, as an instrumental variable. In a Mendelian randomization framework, we assessed the relationships between smoking and impaired cognitive status using the 2010 wave of the Health and Retirement Study. Cognitive status was assessed using cognition tests and categorized in three levels (normal cognition, cognitive impairment-non dementia, dementia). Smoking status was self-reported and classified into never, former, and current smoking. We used multivariable logistic regressions, Wald-type ratio estimators, and two-sample Mendelian randomization methods to examine associations and infer causal relationships. Among European genetic ancestry participants $(n=8741)$, current smoking was associated with cognitive impairment $(\mathrm{OR}=1.62,95 \% \mathrm{Cl}$ : $1.29,2.01)$ relative to normal cognition. Two-sample Mendelian randomization results showed an inferred causal effect of smoking initiation on late-onset Alzheimer's type dementia (MR-Egger: OR $=1.021,95 \% \mathrm{Cl}$ : 1.017, 1.025). We observed no association between current smoking and dementia, or between former smoking and any cognitive status. No associations between smoking status and cognitive status were observed in the African genetic ancestry sample $(n=2501)$. Smoking behavior can give rise to cognitive impairment; therefore, promotion of smoking cessation is also important for brain health. Studies on dose and duration of smoking on cognition are critically needed, as well as continued research in non-European genetic ancestry study samples.

\section{Introduction}

Dementia is a neurodegenerative disorder characterized by difficulties in a person's daily life through memory loss, impaired language function, challenges in problem-solving, and changed cognitive status ${ }^{1}$. In 2018 in the United States (US), 14\% of people age over 70 were living with dementia, which cost an estimated $\$ 277$ billion ${ }^{2}$. Multiple factors contribute to the incidence of dementia, including genetic and environment factors ${ }^{3}$. Cigarette smoking is one of the most prevalent but controversial dementia risk factors. With a prevalence of $20.6 \%$ among adults ${ }^{4}$, smoking could be attributed to $10.8 \%$ of total dementia cases in the US ${ }^{5}$. However, associations between cigarette smoking and dementia in many studies were inconsistent ${ }^{6-8}$, and the causal relationship has not been rigorously assessed.

The likelihood of smoking is partially heritable. Based on meta-analysis, approximately $50 \%$ of the variation in smoking initiation and persistence was attributed to genetic factors ${ }^{9}$. To date, genome-wide association studies (GWAS) have linked 566 genetic variants at 406 loci to smoking initiation, cessation, or heaviness ${ }^{10}$. For example, a single nucleotide polymorphisms (SNP) of the 15q24 nicotinic acetylcholine receptor subunit alpha-5 (CHRNA5) gene (rs16969968[A]), is robustly associated with smoking behavior, and specifically nicotine dependence ${ }^{11}$. Given the large genetic component to smoking, there is an opportunity to use smoking genetic predisposition as an epidemiologic tool.

Moving beyond association testing to rigorously assess causality is crucial for public health prevention. Mendelian randomization is an epidemiologic method using genetic variants as instrumental variables to assess inferred causality. It is analogous to a randomized control trial where individuals are randomized to carry genetic variants that may modify the risk of an exposure. Genetic variants are fixed at conception, which necessarily precedes the onset of exposures and health outcomes. Thus, Mendelian randomization can overcome many drawbacks of observational epidemiology studies, such as the potential for reverse causation, and it is useful when randomized trials would be unethical (as with smoking) ${ }^{12}$. Mendelian randomization has provided evidence for causal relationships between several modifiable risk factors and dementia, including glucose levels ${ }^{13}$, insulin sensitivity ${ }^{14}$, and cholesterol levels ${ }^{15}$. Mendelian randomization studies have also provided evidence that body mass index is not causally associated with Alzheimer's type dementia ${ }^{16,17}$. Two studies have investigated causal effects of smoking on dementia or Alzheimer's type dementia in participants of European ancestry and no causal effect was found using the individual genes, CHRNA5 or BDNF respectively, as instrumental variables ${ }^{18}$. Mendelian randomization studies of smoking and dementia incorporating the broader scope of genetic predisposition to smoking are needed.

To investigate the association between smoking and dementia for causality, in the present study, we applied a Mendelian randomization framework. We first tested for replication of the reported association between smoking and cognitive status in our US nationally representative aging cohort study sample. We next evaluated whether polygenic predisposition to smoking was a valid instrumental variable for smoking status in two genetic ancestry groups. Then we deployed the two-sample Mendelian randomization to test an inferred causal relationship between smoking and dementia status.

\section{Results}

\section{Sample descriptive statistics}

The analytic sample included 11242 participants in the Health and Retirement Study (HRS) Wave 2010 with complete covariate information. Our analytic sample was younger, with lower proportions of never smokers and abnormal cognition compared to the excluded sample $(\mathrm{n}=10786)$ (Supplementary Table 1). Table 1 shows characteristics of our primary analytic sample (European genetic ancestry $n=8741$, African genetic ancestry $n=2501$ ). Distributions of all covariates differed between the European and African genetic ancestry groups, except for proxy status on 
the cognitive test. Specifically, the European ancestry sample had lower proportions of current smokers, abnormal cognition, and chronic health conditions.

Within the European genetic ancestry sample, age, sex, educational attainment, ever drinking alcohol, body mass index, depression score, and histories of stroke, hypertension, and diabetes were associated with both the outcome (cognitive status) and exposure (smoking status) and were treated as covariates in further adjusted models. Proxy respondent status, the number of impaired activities of daily living, and instrumental activities of daily living were also associated with cognitive impairment, though they may be a consequence of impaired cognition. Thus, we did not include those variables in our regression analyses (Table 2).

\section{Assessment of genetic instrumental variable for smoking}

Persons with higher polygenic scores for smoking were more likely to have smoked in the European ancestry sample (Table 3). A one standard deviation increase in smoking polygenic score was associated with $1.33(95 \% \mathrm{Cl}: 1.26,1.40)$ times higher odds of former smoking and 1.52 (95\% $\mathrm{Cl}$ : $1.41,1.63)$ times higher odds of current smoking, relative to never smoking, after adjusting for age, sex, years of education and five ancestryspecific genetic principal components. Formal test statistics confirmed smoking polygenic score as a valid instrument for smoking status (improvement $c^{2}$ : former smoking $(126.2>10)$, current smoking $(127.0>10)$ ).

In the European genetic ancestry sample, polygenic score for smoking was not associated with cognitive status (Table 4), which is an important assumption of Mendelian randomization. A one standard deviation increase in smoking polygenic score was not associated (OR = $1.02,95 \% \mathrm{Cl}$ : $0.93,1.11$ ) with odds of cognitive impairment non-dementia relative to normal cognition in current and never smokers, adjusting for age, sex, years of education, and five ancestry-specific genetic principal components. With adjustment of smoking status, this association remained nonsignificant $(\mathrm{OR}=1.02,95 \% \mathrm{Cl}: 0.93,1.11)$. Together, these findings suggest the polygenic score for smoking is a valid genetic instrumental variable for smoking in relation to cognitive status.

\section{Association between smoking status and cognitive status}

Multivariable logistic regression analysis showed current smoking status was associated with cognitive impairment non-dementia in the European genetic ancestry sample (Table 5). In the primary adjusted model, current smokers relative to never smokers had 1.62 (95\%Cl: $1.29,2.02)$ times odds of cognitive impairment non-dementia relative to normal cognition. This association became attenuated after additional adjustment for health status $(\mathrm{OR}=1.43,95 \% \mathrm{Cl}: 1.12,1.81)$. According to population attributable fraction analysis, in our sample, $11.37 \%$ of the cognitive impairment non-dementia cases were attributed to current smoking. No association was observed between current smoking and dementia, or between former smoking and cognitive status.

Using two sample Mendelian randomization analyses with GWAS summary statistics, we observed a causal relationship between smoking initiation and Alzheimer's type dementia (MR-Egger: OR = 1.021, 95\%Cl: 1.017, 1.025, nSNP = 7,193,484). Thus, smoking initiation in the European genetic ancestry sample may be causally associated with 1.021 times higher odds of Alzheimer's type dementia. As a sensitivity analysis, we also performed a one-sample Mendelian randomization conducted within our HRS sample. However, the association between current smoking and cognitive impairment non-dementia was no longer significant in the one-sample Mendelian randomization framework (OR = $1.06,95 \% \mathrm{Cl}$ : 0.78 , 1.45). This non-causal result was different from the association estimate (without any genetic factors) statistically ( $p$ for heterogeneity $=0.48$ ). Comparing with the two-sample Mendelian randomization results, the one-sample result showed a similar, weak, positive estimate, but with a wider confidence interval.

\section{Sensitivity Analyses}

In the European genetic ancestry sample, there was a weak but significant positive correlation between smoking polygenic score and Alzheimer's disease polygenic score $(r=0.05, p<0.01)$, suggesting one or more pleiotropic genes affect smoking status and cognition simultaneously. To address this, we assessed using the primary smoking SNP (rs16969968) as an instrumental variable. The presence of the rs16969968[A] allele was not associated with smoking status, indicating the SNP was not a valid instrument for smoking status in this sample (Supplementary Table 2). As a negative control check, in the European subsample of never smokers only ( $n=3691)$, smoking polygenic score was not associated with cognitive status (Supplementary Table 3). To assess the age specificity of our results we restricted analyses to participants between ages 60 and 90. Regression and Mendelian randomization results were similar in the older population to the full sample (Supplementary Table 4).

In the African genetic ancestry sample $(\mathrm{n}=2501)$, we also found similar positive association between smoking polygenic score and smoking status. A one standard deviation increase in smoking polygenic score was associated with $1.22(95 \% \mathrm{Cl}: 1.09,1.38)$ times higher odds of former smoking and $1.26(95 \% \mathrm{Cl}: 1.10,1.45)$ times higher odds of current smoking, relative to never smoking, after adjusting for age, sex, years of education and five ancestry-specific genetic principal components. However, no associations were observed between smoking status and cognitive status in logistic regression analyses, so no further one-sample Mendelian randomization analyses were performed (Supplementary Table 5).

\section{Discussion}


This Mendelian randomization analysis was conducted among older adults from the Health and Retirement Study in the 2010 wave. Consistent with prior results, in the European ancestry sample, after adjusting for age, sex, years of education, and five ancestry-specific genetic principal components, we observed a positive association between current smoking and cognitive impairment-non dementia (OR = 1.62, 95\%Cl: $1.29,2.02)$. This is one of the first studies using a genome-wide polygenic score as an instrument (cumulative genetic risk for smoking) with a Mendelian randomization framework to examine the inferred causal relationship between smoking and cognitive status. Two sample Mendelian randomization results showed a causal relationship between smoking initiation and late-onset Alzheimer's type dementia (MR-Egger: OR = 1.021, $95 \% \mathrm{Cl}: 1.017,1.025, \mathrm{nSNP}=7,193,484)$. These findings suggest current smoking may be causally associated with cognitive impairment.

Our multivariable regression association observed between current smoking and cognitive impairment-non dementia in the European ancestry sample was consistent with previous studies ${ }^{19-21}$. Smokers may have elevated chronic oxidative stress in the brain and other organ systems, which may trigger the dementia-pathophysiological processes. Computed tomography and magnetic resonance based studies also found supportive evidence of abnormalities in brain morphology, perfusion and neurochemistry in smokers ${ }^{22}$. Our null associations between former smoking and cognitive impairment were also similar to previous studies ${ }^{23,24}$. Although there are several hypothesized pathways through which smoking may influence cognitive function, we were not able to identify specific mechanisms in this study.

It is crucial to follow up association studies with methods to assess causality, such as Mendelian randomization. Informed by prior association studies, in coronary artery disease for example, Mendelian randomization provided evidence for a causal relationship with low density lipoprotein levels ${ }^{25}$, as well as importantly showed no causal relationship with C-reactive protein ${ }^{26}$. In Alzheimer's dementia specifically, Mendelian randomization studies provided evidence that body mass index is not a causal risk factor ${ }^{16,17}$. Identifying causal and non-causal factors can help direct limited public health prevention resources to causal factors as well as inform mechanisms of disease.

In this study, we used both two-sample and one-sample Mendelian randomization models to evaluate causality to balance power and assumptions. By incorporating data from multiple sources including large consortia, two-sample Mendelian randomization provides an opportunity to substantially increase the statistical power of the test. The MR Egger regression method used in our analyses also has the advantage of allowing one or more genetic variants to have pleiotropic effects. ${ }^{27}$ With the two sample Mendelian randomization, we observed a causal relationship between smoking initiation and late-onset Alzheimer's type dementia (MR-Egger: OR = 1.021, 95\%Cl: 1.017, 1.025, nSNP = 7,193,484). Given that summary statistics used in the two-sample Mendelian randomization were from published large GWAS consortia, it is possible that the instrument-exposure and instrument-outcome datasets partially overlap if studies participated in both consortia. Partially overlapping samples might introduce weak instrument bias, which is towards the exposure-outcome estimate ${ }^{27}$. Our one-sample Mendelian randomization was less powered, as our analyses were restricted to the HRS sample data. We observed a similar estimate with the one-sample Mendelian randomization analysis using Wald-type/ratio method, but a much wider confidence interval $(\mathrm{OR}=1.06,95 \% \mathrm{Cl}: 0.78,1.45)$. To better understand the potential reasons for the difference between the two-sample and one-sample results, we further performed a thorough evaluation of several assumptions to assess the validity of the one-sample method. We performed formal tests to assess the smoking polygenic score as a valid instrument for smoking status in the European ancestry sample. We observed that this relevance assumption was met. Although the independence and exclusion restriction assumptions cannot be tested pragmatically, we made several attempts to test for potential violation. First, we performed a negative control analysis among never smokers that supported the satisfaction of these two assumptions. However, the significant association between smoking polygenic score and Alzheimer's disease polygenic score suggested the existence of pleiotropy. This possible violation of the exclusion restriction may be an issue, given evidence showing that the smoking polygenic score was also associated with multiple confounders such as history of hypertension and stroke, body mass index, and depression score (Supplementary Fig. 1). Taken as a whole, we are limited to testing inferred causality in this study sample using Mendelian randomization methods.

This study has several strengths. First, studies examining smoking status and cognitive function in the context of genetics are limited, and thus our findings contribute to an important, yet sparse, literature. Second, instead of using a single SNP, which only accounts for a very small fraction of variability of the incidence of the disease or behavior, we used multiple variants (summarized in a polygenic score) to increase the amount of variation explained, and thus, increased the power of testing our hypotheses ${ }^{28}$. Additionally, we included large, representative samples of two genetic ancestry groups in our study, which is important given that non-European ancestries are unrepresented in genetic studies ${ }^{29}$. The inferred causal association between current smoking and cognitive impairment was found in the European ancestry sample only, so our results might have limited generalizability to other ancestral groups ${ }^{29}$. We had a relatively small sample of African genetic ancestry participants (African genetic ancestry $n=2501$ versus European genetic ancestry $n=8741$ ). Thus, we were not surprised by the null association observed in the African ancestry sample. A similar study should be replicated in an African genetic ancestry sample with a larger sample size.

Selective survival is a concern for both dementia and smoking. Smokers may die prematurely from other smoking-related diseases before developing dementia. To address this, we excluded participants older than age 90 and the oldest birth cohort, focusing our analyses on younger participants. Within the Health and Retirement Study, the genotyped respondents were longer-lived as compared with their non-genotyped respondents ${ }^{30}$. The development of other smoking-related morbidity, such as cardiovascular diseases and cancer, may also impede participation in the longitudinal Health and Retirement Study. Thus, our sample might be biased toward healthier smokers - individuals who survived or did not 
experience significant smoking-related morbidity, and the smoking-dementia relationship was likely underestimated. This potential survival bias could also explain the null association between smoking and dementia found in our European sample $(\mathrm{OR}=1.13,95 \% \mathrm{Cl}$ : $0.66,1.87)$.

Several limitations to this work are worth noting. First, although we attempted to account for confounding and population stratification, we are cautious about the findings. Future studies are warranted to replicate out findings in other cohorts and study populations. Second, cumulative genetic risk scores are subjective to weak instrument bias, meaning that if only one of the genetic variants is not a valid instrumental variable, the causal estimate will be biased and false positive error rates will be inflated ${ }^{31}$. Third, cognitive status is not as well-defined as other more explicitly defined variables, such as smoking status, and was examined at only one time point, which almost certainly does not completely account for the lifetime variation in the trait instrumented by the genes. Next steps should include examining cognitive trajectories and dementia incidence. Results could also be strengthened by using more expansive smoking variables (such as number of cigarettes consumed or duration of smoking), and a longitudinal assessment of incident dementia.

Smoking behaviors are partially modifiable, which can be effectively altered, and promote a healthier aging population. Our study provided evidence to support a positive association between current smoking and cognitive impairment, and a causal relationship between smoking initiation and Alzheimer's type dementia. The null effect of former smoking suggests, while preliminary, a plausible protective effect of smoking cessation. Promotion of smoking cessation could be an effective strategy for lowering dementia prevalence over time at the population level.

In conclusion, in a cross-sectional analysis of the Health and Retirement Study, we observed current smoking was associated with cognitive impairment in older European ancestry adults, which is consistent with prior research. We conducted a two-sample Mendelian randomization analysis and observed an inferred causal relationship between smoking and impaired cognition. Interventions targeting contributing, confounding, or mediating pathways of this association may help attenuate the risk of cognitive impairment. Additional studies on dose and time-span effect of smoking behaviors on cognitive impairment are critically needed, as well as larger studies in diverse genetic ancestry study samples. Cessation of smoking is critical for public health more broadly, as well as cognitive health more specifically, shown here.

\section{Methods}

\section{Study population and design}

This cross-sectional study used the 2010 wave of the Health and Retirement Study, a publicly available national longitudinal panel study of individuals aged over 50 in the US ${ }^{32}$. The Health and Retirement Study has collected data on health and economic information related to aging every two years since 1992 and more than 43,000 individuals have participated to date ${ }^{33}$.

Detailed sample selection steps are shown in Supplementary Fig. 2. Since the risk factors and underlying neuropathological features of dementia are considerably different for people aged under 50 or over $90^{34}$, we excluded participants who were in these age groups, as well as those in the Asset and Health Dynamics among the Oldest Old and Children of the Depression study, the two oldest cohorts of the Health and Retirement Study

${ }^{35}$. Given the characteristics of progressive and irreversible cognition decline, we excluded individuals with reversed cognition, who were classified as normal cognition in 2010 but dementia in 2008, to minimize misclassification of cognitive status. To avoid potential recall bias, we also excluded those self-reported never smoking in 2010 but reported former or current smoking in 2008.

\section{Cognitive status assessment}

The main outcome variable in this analysis, cognitive status, was categorized in three levels as normal, cognitive impairment-non dementia, or dementia. The categorization method depended on whether the respondent could participate in the interview themselves or required a proxy respondent due to physical or cognitive problems. Self-respondent categories were based on a 27-point scale, according to participants' performance on a series of cognition tests, including immediate and delayed 10-noun free recall, serial 7 subtraction, and backward count from 20

36. The proxy-respondent categories were based on an 11-point scale, using the proxy's assessment of the respondent's memory, whether the respondent had limitations in instrumental activities of daily living, and whether the respondent had difficulty completing the interview because of a cognitive limitation. Cognitive status cut points were established by Crimmins et al. and have been validated clinically and empirically with an area under curve score of $0.84^{37}$. All cognition-related data were retrieved from the cross-wave imputation of cognitive functioning data provided by the Health and Retirement Study ${ }^{38}$.

\section{Exposure assessment and covariates}

Smoking status was self-reported and classified into never, former, and current smoking ${ }^{39}$. Smoking was defined as more than 100 cigarettes in a respondent's lifetime (do not include pipes or cigars).

Other covariates used in our analysis included demographic characteristics, behavioral risk factors, and chronic health conditions. Age (years) was calculated by current wave year minus self-reported year of birth. Sex (male/female), years of education, proxy status (self/proxy-respondent), body mass index (kilograms/meters ${ }^{2}$ ), alcohol consumption (ever drinking yes/no), and histories of hypertension, diabetes, and stroke (yes/no) were 
self-reported. Center for Epidemiologic Studies of Depression (CESD) score of depressive symptoms was based on self-reported feelings in the past week (the higher the score, the more negative the respondent's feelings). Activities of daily living (ADL) and instrumental activities of daily living (IADL) were self/proxy-reported according to proxy status, representing number of difficulties in performing two sets of tasks (ADL: bathing, eating, dressing, walking across a room, and getting in or out of bed; IADL: using a telephone, taking medication, handling money, shopping, and preparing meals). All variables were assessed at the 2010 wave and retrieved from the RAND Health and Retirement Study Longitudinal File ${ }^{39}$.

\section{Genetic data}

Respondents provided saliva samples after reading and signing a consent form during an enhanced face-to-face interview. Genotype measures were obtained using the Illumina HumanOmni2.5 BeadChip and genotyping was conducted by the Center for Inherited Disease Research. Genotype data that passed initial quality control were released to and analyzed by the Quality Assurance/Quality Control analysis team at the University of Washington. Details of the genotype collection and quality control are available elsewhere ${ }^{40}$.

We used a polygenic score for smoking as the instrumental variable in our primary analysis. A polygenic score is a single quantitative measure of genetic risk, which aggregates multiple individual loci across the human genome and weights them by effect sizes derived from a GWAS. The smoking polygenic scores were created using SNPs and weights identified by a 2019 GWAS meta-analysis conducted by the GWAS \& Sequencing Consortium of Alcohol and Nicotine use (GSCAN) ${ }^{10}$. The Alzheimer's disease polygenic scores used in sensitivity analysis were created using results from a 2019 GWAS conducted by Kunkle et al. excluding the APOE region ${ }^{41}$. All the polygenic scores were standardized to a standard normal curve (mean $=0$, standard deviation $=1$ ) within genetic ancestry groups.

Genetic ancestry was identified through the union of self-reported race/ethnicity and principal component analysis on genome-wide SNPs calculated across all participants. Ancestry-specific genetic principal components were created in each ancestry sample by another principal component analysis to adjust for hidden population structure within ancestry. A binary variable of $A P O E-\varepsilon 4$ allele carrier (having at least one copy of the $\varepsilon 4$ allele, yes/no), and a categorical variable of smoking susceptibility rs $16969968[\mathrm{~A}]$ carrier (0/1/2 copies) were derived from the imputed genetic data in the Health and Retirement Study which used a worldwide 1000 Genomes Project reference panel (phase I) ${ }^{42}$. All genetic data were downloaded from published datasets by the Health and Retirement Study 43.

\section{Statistical analyses}

Analyses were carried out separately for European and African genetic ancestry groups. We used the $\chi^{2}$ test and analysis of variance as appropriate to examine differences in baseline characteristics across included/excluded samples, different ancestry groups, exposure and outcome groups. Linear regression analysis was used to examine the associations of smoking polygenic score with other covariates.

An ordinal logistic regression was tried first to assess the proportional association between the three-level smoking and cognition variables. However, we observed a violation of the proportional odds assumption at all variables, except the smoking polygenic score, indicating heterogenous associations across different levels of smoking and cognitive status. Thus, we performed multivariable logistic regressions in four subsets of each ancestry sample, using never smoking and normal cognition as the reference groups. Primary models were adjusted for age, sex, years of education, and five ancestry-specific genetic principal components. Additional adjustment included dementia risk factors that were associated with smoking status. The results were presented as odds ratios (ORs) and 95\% confidence interval (95\%Cls). Population attributable fractions were also calculated for significant associations. $P$ value $<.05$ was considered for statistical significance if not specified. Our primary analyses were in the European ancestry. The conceptual directed acyclic graph and study subsets are shown in Fig. 1.

Late-onset Alzheimer's disease is the most common form of dementia and may contribute to $60-70 \%$ of cases ${ }^{34}$. Thus, we used late-onset Alzheimer's disease as the outcome phenotype for our two-sample Mendelian randomization study. We performed the two-sample Mendelian randomization analysis using the summary statistics from the same two GWASs (2019 GSCAN smoking ${ }^{10}$ and 2019 Kunkle Alzheimer's disease ${ }^{41}$ ) that were used for polygenic score construction. We used the Mendelian randomization-Egger (MR-Egger) method ${ }^{44}$, which implemented an adaption of Egger regression in Mendelian randomization study to allow for pleiotropic effects, with all overlapped SNPs in these two GWASs. We assumed that samples from these two GWASs were independent and no pruning of SNPs in linkage disequilibrium was performed. Mendelian Randomization results were also presented as ORs and 95\%Cls. The two-sample Mendelian randomization was performed using the R package TwoSampleMR (version 0.5.6) ${ }^{45}$.

\section{Sensitivity analyses}

We used the R package MendelianRandomization (version 0.4.2) ${ }^{46}$ to conduct an one-sample Mendelian randomization analysis, where the association of genetic variant with the exposure and with the outcome are estimated in the same sample ${ }^{47}$, to examine whether smoking polygenic score was associated with cognitive status through its associations with smoking status. To evaluate the strength of the instrument, we used improvement $\chi^{2}$ from the first-stage logistic regression, with values greater than 10 being taken as evidence against weak instruments 27 . Wald-type ratio estimators were used to calculate the causal effect of smoking on cognitive status and the Delta method was used to estimate standard errors ${ }^{27}$. To evaluate heterogeneity, we compared results from the Mendelian randomization analyses with standard logistic regression 
using interaction tests ${ }^{48}$. Mendelian randomization methods are based on the following three assumptions: 1) relevance assumption: the genetic variants associate with the risk factor of interest; 2 ) independence assumption: there are no unmeasured confounders of the association between genetic variants and outcome; 3 ) exclusion restriction: the genetic variants affect the outcome only through the effect on the risk factor of interest

27. To test the robustness of the observed associations, we performed several sensitivity analyses to assess the potential violation of these assumptions. To check for pleiotropy, we tested for associations between the smoking polygenic score and general cognition polygenic score in our study sample. We also used a single SNP (rs16969968) as an instrumental variable instead to re-evaluate its associations with cognitive status. We further examined the association between smoking polygenic score and cognitive status in never smokers only, which served as a negative control.

The apolipoprotein $\mathrm{E}(A P O E) \varepsilon 4$ allele polymorphism is by far the strongest independent genetic risk factor for dementia ${ }^{49}$. We added in $A P O E-\varepsilon 4$ allele carrier as a precision variable in our sensitivity analysis to reduce the standard errors of the regression models and hence shrink confidence intervals on coefficients of interest. Finally, we repeated our standard logistic regression analyses in an older population (age $\geq 60$ and $\leq 90$ ).

All analyses were conducted in R version 3.5.1 ${ }^{50}$. Code to produce all analyses in this manuscript are available (https://github.com/bakulskilab).

\section{Declarations}

Acknowledgments: We thank the participants of the Health and Retirement Study as well as the Health and Retirement Study staff for their data collection services.

Author Contributions: Conceptualization, E.B.W. and K.M.B.; methodology, M.F.; validation, Y.J.; formal analysis, M.F.; data curation, E.B.W. and M.F.; writing-original draft preparation, M.F.; writing-review and editing, K.M.B., E.B.W, and J.D.F.; supervision, E.B.W. and K.M.B.; funding acquisition, E.B.W. and K.M.B. All authors have read and agreed to the published version of the manuscript.

Conflicts of Interest: The authors declare no conflict of interest.

Institutional Review Board Statement: The Health and Retirement Study is sponsored by the National Institute on Aging (NIA U01AG009740) and is conducted by the University of Michigan, where written informed consent was approved by the Institutional Review Board. This secondary data analysis was exempt and not regulated, as determined by the Institutional Review Board at the University of Michigan (HUM00128220).

Informed Consent Statement: Informed consent was obtained from all individual participants included in the study.

Data Availability Statement: All data used in this study were publicly available and can be retrieved from the Health and Retirement Study website upon requests (https://hrs.isr.umich.edu/data-products/access-to-public-data). Code to produce all analyses in this manuscript are available (https://github.com/bakulskilab).

Funding: All authors were supported by grants from the National Institute on Aging (R01 AG055406, R01 AG067592). Dr. Bakulski was supported by grants from the National Institute for Environmental Health Sciences and the National Institute for Minority Health and Health Disparities (R01 ES025531; R01 ES025574; and R01 MD013299). Dr. Ware and Faul were both supported by a grant from the National Institute on Aging (R01 AG055654). Dr. Ware was additionally supported by a grant from the National Institute for Minority Health and Health Disparities (R01 MD012145). This work was supported by the University of Michigan, Michigan Lifestage Environmental Exposures and Disease (M-LEEaD) National Institute for Environmental Health Sciences Core Center (P30 ES017885), the Michigan Alzheimer's Disease Center (P30 AG053760), and the Michigan Center for the Demography of Aging (P30 AG012846).

\section{References}

1. McKhann, G. M. et al. The diagnosis of dementia due to Alzheimer's disease: recommendations from the National Institute on AgingAlzheimer's Association workgroups on diagnostic guidelines for Alzheimer's disease. Alzheimers Dement7, 263-269 (2011).

2. Facts and Figures. Alzheimer's Disease and Dementia https://alz.org/alzheimers-dementia/facts-figures.

3. Jellinger, K. A. The enigma of mixed dementia. Alzheimers Dement3, 40-53 (2007).

4. Jamal, A. et al. Current Cigarette Smoking Among Adults - United States, 2016. MMWR Morb. Mortal. Wkly. Rep.67, 53-59 (2018).

5. Barnes, D. E. \& Yaffe, K. The projected effect of risk factor reduction on Alzheimer's disease prevalence. Lancet Neuro/10, 819-828 (2011).

6. Lee, P. N. Smoking and Alzheimer's disease: a review of the epidemiological evidence. Neuroepidemiology13, 131-144 (1994).

7. Van Duijn, C. M. et al. Interaction between genetic and environmental risk factors for Alzheimer's disease: a reanalysis of case-control studies. Genet. Epidemiol.11, 539-551 (1994).

8. Anstey, K. J., von Sanden, C., Salim, A. \& O’Kearney, R. Smoking as a risk factor for dementia and cognitive decline: a meta-analysis of prospective studies. Am. J. Epidemiol.166, 367-378 (2007).

Page $7 / 15$ 
9. Li, M. D., Cheng, R., Ma, J. Z. \& Swan, G. E. A meta-analysis of estimated genetic and environmental effects on smoking behavior in male and female adult twins. Addiction98, 23-31 (2003).

10. Liu, M. et al. Association studies of up to 1.2 million individuals yield new insights into the genetic etiology of tobacco and alcohol use. Nat. Genet.51, 237-244 (2019).

11. Ware, J. J., van den Bree, M. B. M. \& Munafò, M. R. Association of the CHRNA5-A3-B4 Gene Cluster With Heaviness of Smoking: A MetaAnalysis. Nicotine Tob Res13, 1167-1175 (2011).

12. Smith, G. D. \& Ebrahim, S. 'Mendelian randomization': can genetic epidemiology contribute to understanding environmental determinants of disease? Int J Epidemio/32, 1-22 (2003).

13. Benn, M., Nordestgaard, B. G., Tybjærg-Hansen, A. \& Frikke-Schmidt, R. Impact of glucose on risk of dementia: Mendelian randomisation studies in 115,875 individuals. Diabetologia63, 1151-1161 (2020).

14. Walter, S. et al. Diabetic Phenotypes and Late-Life Dementia Risk: A Mechanism-specific Mendelian Randomization Study. Alzheimer Dis Assoc Disord30, 15-20 (2016).

15. Zhang, X. et al. Causal association of circulating cholesterol levels with dementia: a mendelian randomization meta-analysis. Transl Psychiatry10, 145 (2020).

16. Mukherjee, S. et al. Genetically predicted body mass index and Alzheimer's disease-related phenotypes in three large samples: Mendelian randomization analyses. Alzheimers Dement11, 1439-1451 (2015).

17. Nordestgaard, L. T., Tybjærg-Hansen, A., Nordestgaard, B. G. \& Frikke-Schmidt, R. Body Mass Index and Risk of Alzheimer's Disease: A Mendelian Randomization Study of 399,536 Individuals. J Clin Endocrinol Metab102, 2310-2320 (2017).

18. Kuźma, E. et al. Which Risk Factors Causally Influence Dementia? A Systematic Review of Mendelian Randomization Studies. J Alzheimers Dis64, 181-193.

19. Aggarwal, N. T. et al. The relation of cigarette smoking to incident Alzheimer's disease in a biracial urban community population. Neuroepidemiology26, 140-146 (2006).

20. Juan, D. et al. A 2-year follow-up study of cigarette smoking and risk of dementia. Eur. J. Neurol.11, 277-282 (2004).

21. Ott, A. et al. Smoking and risk of dementia and Alzheimer's disease in a population-based cohort study: the Rotterdam Study. Lancet351, 1840-1843 (1998).

22. Durazzo, T. C., Meyerhoff, D. J. \& Nixon, S. J. Chronic cigarette smoking: implications for neurocognition and brain neurobiology. Int J Environ Res Public Health7, 3760-3791 (2010).

23. Reitz, C., den Heijer, T., van Duijn, C., Hofman, A. \& Breteler, M. M. B. Relation between smoking and risk of dementia and Alzheimer disease: the Rotterdam Study. Neurology69, 998-1005 (2007).

24. Merchant, C. et al. The influence of smoking on the risk of Alzheimer's disease. Neurology52, 1408-1412 (1999).

25. Ference, B. A., Majeed, F., Penumetcha, R., Flack, J. M. \& Brook, R. D. Effect of naturally random allocation to lower low-density lipoprotein cholesterol on the risk of coronary heart disease mediated by polymorphisms in NPC1L1, HMGCR, or both: a $2 \times 2$ factorial Mendelian randomization study. J Am Coll Cardio/65, 1552-1561 (2015).

26. Jansen, H., Samani, N. J. \& Schunkert, H. Mendelian randomization studies in coronary artery disease. Eur Heart J35, 1917-1924 (2014).

27. Davies, N. M., Holmes, M. V. \& Davey Smith, G. Reading Mendelian randomisation studies: a guide, glossary, and checklist for clinicians. BMJ362, k601 (2018).

28. Davey Smith, G. \& Hemani, G. Mendelian randomization: genetic anchors for causal inference in epidemiological studies. Hum. Mol. Genet.23, R89-98 (2014).

29. Martin, A. R. et al. Human Demographic History Impacts Genetic Risk Prediction across Diverse Populations. Am. J. Hum. Genet.100, 635-649 (2017).

30. Domingue, B. W. et al. Mortality selection in a genetic sample and implications for association studies. Int J Epidemio/46, 1285-1294 (2017).

31. Burgess, S., Bowden, J., Fall, T., Ingelsson, E. \& Thompson, S. G. Sensitivity Analyses for Robust Causal Inference from Mendelian Randomization Analyses with Multiple Genetic Variants. Epidemiology28, 30-42 (2017).

32. Ware, E. B. et al. Heterogeneity in polygenic scores for common human traits. bioRxiv 106062 (2017) doi:10.1101/106062.

33. Sonnega, A. et al. Cohort Profile: the Health and Retirement Study (HRS). Int J Epidemio/43, 576-585 (2014).

34. Bullain, S. S. \& Corrada, M. M. Dementia in the oldest old. Continuum (Minneap Minn)19, 457-469 (2013).

35. Health and Retirement Study (HRS) \& Asset and Health Dynamics among the Oldest Old (AHEAD) | sgim.org. https://www.sgim.org/communities/research/dataset-compendium/health-and-retirement-study-hrs-asset-and-health-dynamics-among-theoldest-old-ahead.

36. Ofstedal, M. B. \& Fisher, G. Documentation of Cognitive Functioning Measures in the Health and Retirement Study. http://hrsonline.isr.umich.edu/sitedocs/userg/dr-006.pdf (2005) doi:10.7826/ISR-UM.06.585031.001.05.0010.2005.

Page 8/15 
37. Crimmins, E. M., Kim, J. K., Langa, K. M. \& Weir, D. R. Assessment of Cognition Using Surveys and Neuropsychological Assessment: The Health and Retirement Study and the Aging, Demographics, and Memory Study. J Gerontol B Psychol Sci Soc Sci66B, i162-i171 (2011).

38. Fisher, G., Hassan, H., Faul, J., Rogers, W. \& Weir, D. Health and Retirement Study Imputation of Cognitive Functioning Measures: $1992-2014$. (2017).

39. Monica, 1776 Main Street Santa \& California 90401-3208. RAND HRS Longitudinal File 2016 (V1). https://www.rand.org/well-being/socialand-behavioral-policy/centers/aging/dataprod/hrs-data.html.

40. David R., W. Quality Control Report for Genotypic Data. (2013).

41. Kunkle, B. W. et al. Genetic meta-analysis of diagnosed Alzheimer's disease identifies new risk loci and implicates $A \beta$, tau, immunity and lipid processing. Nat Genet51, 414-430 (2019).

42. Imputation Report - 1000 Genomes Project reference panel. (2013).

43. Genetic Data | Health and Retirement Study. https://hrs.isr.umich.edu/data-products/genetic-data.

44. Bowden, J., Davey Smith, G. \& Burgess, S. Mendelian randomization with invalid instruments: effect estimation and bias detection through Egger regression. Int J Epidemio/44, 512-525 (2015).

45. Introduction. https://mrcieu.github.io/TwoSampleMR/articles/introduction.html.

46. Olena, Y. Mendelian Ramdomization. https://www.ncbi.nlm.nih.gov/projects/gap/cgi-bin/study.cgi?study_id=phs000428.v2.p2.

47. Pagoni, P., Dimou, N. L., Murphy, N. \& Stergiakouli, E. Using Mendelian randomisation to assess causality in observational studies. Evid Based Ment Health22, 67-71 (2019).

48. Altman, D. G. \& Bland, J. M. Interaction revisited: the difference between two estimates. BMJ326, 219 (2003).

49. Rasmussen, K. L., Tybjærg-Hansen, A., Nordestgaard, B. G. \& Frikke-Schmidt, R. Absolute 10-year risk of dementia by age, sex and APOE genotype: a population-based cohort study. CMAJ190, E1033-E1041 (2018).

50. R: The R Project for Statistical Computing. https://www.r-project.org/.

\section{Tables}

Table 1. Characteristics of study sample participants $(n=11242)$ stratified by genetic ancestry, Health and Retirement Study, Wave $2010^{a}$ 


\begin{tabular}{|c|c|c|c|c|}
\hline & Overall & European ancestry & African ancestry & \multirow{2}{*}{ P-value ${ }^{b}$} \\
\hline & $\mathrm{n}=11242$ & $\mathrm{n}=8741$ & $n=2501$ & \\
\hline \multicolumn{5}{|c|}{ Categorical Variables [Count (Frequency)] } \\
\hline Smoking status at Wave 2010 & & & & \multirow[t]{4}{*}{$<0.001^{\star}$} \\
\hline Never & $4659(41.4 \%)$ & $3691(42.2 \%)$ & $968(38.7 \%)$ & \\
\hline Former & $4768(42.4 \%)$ & $3823(43.7 \%)$ & $945(37.8 \%)$ & \\
\hline Current & $1815(16.1 \%)$ & $1227(14.0 \%)$ & $588(23.5 \%)$ & \\
\hline \multicolumn{4}{|l|}{ Cognitive Status at Wave 2010} & \multirow[t]{4}{*}{$<0.001^{\star}$} \\
\hline Normal & $9307(82.8 \%)$ & $7654(87.6 \%)$ & $1653(66.1 \%)$ & \\
\hline Cognitive Impairment-Non Dementia & $1572(14.0 \%)$ & $894(10.2 \%)$ & $678(27.1 \%)$ & \\
\hline Dementia & $363(3.23 \%)$ & $193(2.21 \%)$ & $170(6.80 \%)$ & \\
\hline Sex (Female) & $6307(56.1 \%)$ & $4802(54.9 \%)$ & $1505(60.2 \%)$ & $<0.001 *$ \\
\hline Stroke history (Yes) & $718(6.39 \%)$ & $502(5.75 \%)$ & $216(8.64 \%)$ & $<0.001^{*}$ \\
\hline Hypertension history (Yes) & $6492(57.8 \%)$ & $4723(54.1 \%)$ & $1769(70.8 \%)$ & $<0.001 *$ \\
\hline Diabetes history (Yes) & $2308(20.5 \%)$ & $1597(18.3 \%)$ & $711(28.5 \%)$ & $<0.001 *$ \\
\hline Drink status (Ever drinker) & $6603(58.7 \%)$ & $5342(61.1 \%)$ & $1261(50.4 \%)$ & $<0.001^{*}$ \\
\hline Proxy status (Self-respondent) & $11039(98.2 \%)$ & $8573(98.1 \%)$ & $2466(98.6 \%)$ & 0.10 \\
\hline$A P O E-\varepsilon 4$ allele carrier (Yes) & $2678(28.7 \%)$ & $1981(26.4 \%)$ & $697(38.0 \%)$ & $<0.001 *$ \\
\hline \multicolumn{4}{|l|}{ Copies of rs16969968[A] allele } & \multirow[t]{4}{*}{$<0.001^{*}$} \\
\hline 0 & $4657(52.9 \%)$ & $3084(43.8 \%)$ & $1573(89.3 \%)$ & \\
\hline 1 & $3379(38.4 \%)$ & $3197(45.4 \%)$ & $182(10.3 \%)$ & \\
\hline 2 & $773(8.78 \%)$ & 767 (10.9\%) & $6(0.34 \%)$ & \\
\hline \multicolumn{5}{|l|}{ Continuous Variables [Mean (SD)] } \\
\hline Age (yrs) & $65.0(8.93)$ & $65.8(8.86)$ & $62.2(8.62)$ & $<0.001 *$ \\
\hline School years (yrs) & $13.2(2.54)$ & $13.4(2.44)$ & $12.4(2.69)$ & $<0.001^{\star}$ \\
\hline Body Mass Index $\left(\mathrm{kg} / \mathrm{m}^{2}\right)$ & $28.9(6.22)$ & $28.4(5.89)$ & $30.5(7.03)$ & $<0.001 *$ \\
\hline Activities of daily living & $0.26(0.80)$ & $0.22(0.71)$ & $0.43(1.01)$ & $<0.001^{*}$ \\
\hline Instrumental activities of daily living & $0.22(0.72)$ & $0.19(0.66)$ & $0.34(0.86)$ & $<0.001^{*}$ \\
\hline CESD score & $1.36(1.93)$ & $1.22(1.87)$ & $1.83(2.07)$ & $<0.001^{\star}$ \\
\hline
\end{tabular}

Abbreviations: APOE, Apolipoprotein E; CESD, Center for Epidemiological Studies Depression; SD, Standard Deviation.

\section{Notes:}

[a] All the statistics including count, frequency, mean, SD, and P value were calculated based on non-missing data for each variable.

[b] The overall P value was calculated from chi-square test or analysis of variance for categorical or continuous variables as appropriate, interpreted as differences between groups.

Table 2. Bivariate characteristics stratified by cognitive or smoking status, Health and Retirement Study, Wave 2010, European ancestry sample ( $=$ $8741)^{a}$ 


\begin{tabular}{|c|c|c|c|c|c|c|c|c|c|}
\hline & \multirow[b]{2}{*}{ Overall } & \multicolumn{4}{|c|}{ Cognitive Status } & \multicolumn{4}{|c|}{ Smoking Status } \\
\hline & & Normal & Impaired & Dementia & \multirow[t]{2}{*}{ P-value ${ }^{b}$} & Never & Former & Current & \multirow[t]{2}{*}{ P-value ${ }^{b}$} \\
\hline & $\begin{array}{r}n= \\
8741\end{array}$ & $\begin{array}{r}n= \\
7654\end{array}$ & $\begin{array}{c}n= \\
894\end{array}$ & $\begin{array}{c}n= \\
193\end{array}$ & & $\begin{array}{r}n= \\
3691\end{array}$ & $\begin{array}{r}n= \\
3823\end{array}$ & $\begin{array}{r}n= \\
1227\end{array}$ & \\
\hline \multicolumn{10}{|c|}{$\begin{array}{l}\text { Categorical Variables [Count } \\
\text { (Frequency)] }\end{array}$} \\
\hline \multicolumn{5}{|l|}{ Smoking status } & \multirow[t]{4}{*}{$<0.001^{*}$} & \multirow[t]{4}{*}{-} & & & \\
\hline Never & $\begin{array}{l}3691 \\
(42.2 \%)\end{array}$ & $\begin{array}{l}3315 \\
(43.3 \%)\end{array}$ & $\begin{array}{l}311 \\
(34.8 \%)\end{array}$ & $\begin{array}{l}65 \\
(33.7 \%)\end{array}$ & & & & & \\
\hline Former & $\begin{array}{l}3823 \\
(43.7 \%)\end{array}$ & $\begin{array}{l}3307 \\
(43.2 \%)\end{array}$ & $\begin{array}{l}412 \\
(46.1 \%)\end{array}$ & $\begin{array}{l}104 \\
(53.9 \%)\end{array}$ & & & & & \\
\hline Current & $\begin{array}{l}1227 \\
(14.0 \%)\end{array}$ & $\begin{array}{l}1032 \\
(13.5 \%)\end{array}$ & $\begin{array}{l}171 \\
(19.1 \%)\end{array}$ & $\begin{array}{l}24 \\
(12.4 \%)\end{array}$ & & & & & \\
\hline Sex (Female) & $\begin{array}{l}4802 \\
(54.9 \%)\end{array}$ & $\begin{array}{l}4325 \\
(56.5 \%)\end{array}$ & $\begin{array}{l}395 \\
(44.2 \%)\end{array}$ & $\begin{array}{l}82 \\
(42.5 \%)\end{array}$ & $<0.001^{\star}$ & $\begin{array}{l}2323 \\
(62.9 \%)\end{array}$ & $\begin{array}{l}1803 \\
(47.2 \%)\end{array}$ & $\begin{array}{l}676 \\
(55.1 \%)\end{array}$ & $<0.001^{*}$ \\
\hline Stroke (Yes) & $\begin{array}{l}512 \\
(5.86 \%)\end{array}$ & $\begin{array}{l}344 \\
(4.49 \%)\end{array}$ & $\begin{array}{l}110 \\
(12.3 \%)\end{array}$ & $\begin{array}{l}58 \\
(30.2 \%)\end{array}$ & $<0.001^{\star}$ & $\begin{array}{l}176 \\
(4.77 \%)\end{array}$ & $\begin{array}{l}245 \\
(6.41 \%)\end{array}$ & $\begin{array}{l}91 \\
(7.42 \%)\end{array}$ & $<0.001^{*}$ \\
\hline Hypertension (Yes) & $\begin{array}{l}4723 \\
(54.1 \%)\end{array}$ & $\begin{array}{l}4033 \\
(52.8 \%)\end{array}$ & $\begin{array}{l}553 \\
(61.9 \%)\end{array}$ & $\begin{array}{l}137 \\
(71.4 \%)\end{array}$ & $<0.001^{*}$ & $\begin{array}{l}1911 \\
(51.8 \%)\end{array}$ & $\begin{array}{l}2217 \\
(58.1 \%)\end{array}$ & $\begin{array}{l}595 \\
(48.5 \%)\end{array}$ & $<0.001^{*}$ \\
\hline Diabetes (Yes) & $\begin{array}{l}1597 \\
(18.3 \%)\end{array}$ & $\begin{array}{l}1319 \\
(17.2 \%)\end{array}$ & $\begin{array}{l}230 \\
(25.7 \%)\end{array}$ & $\begin{array}{l}48 \\
(24.9 \%)\end{array}$ & $<0.001^{\star}$ & $\begin{array}{l}650 \\
(17.6 \%)\end{array}$ & $\begin{array}{l}759 \\
(19.9 \%)\end{array}$ & $\begin{array}{l}188 \\
(15.3 \%)\end{array}$ & $0.001 *$ \\
\hline Drink status (Ever drinker) & $\begin{array}{l}5342 \\
(61.1 \%)\end{array}$ & $\begin{array}{l}4887 \\
(63.8 \%)\end{array}$ & $\begin{array}{l}411 \\
(46.0 \%)\end{array}$ & $\begin{array}{l}44 \\
(22.8 \%)\end{array}$ & $<0.001^{\star}$ & $\begin{array}{l}2074 \\
(56.2 \%)\end{array}$ & $\begin{array}{l}2528 \\
(66.1 \%)\end{array}$ & $\begin{array}{l}740 \\
(60.3 \%)\end{array}$ & $<0.001^{*}$ \\
\hline $\begin{array}{l}\text { Proxy status (Self- } \\
\text { respondent) }\end{array}$ & $\begin{array}{l}8573 \\
(98.1 \%)\end{array}$ & $\begin{array}{l}7595 \\
(99.2 \%)\end{array}$ & $\begin{array}{l}864 \\
(96.6 \%)\end{array}$ & $\begin{array}{l}114 \\
(59.1 \%)\end{array}$ & $<0.001^{\star}$ & $\begin{array}{l}3637 \\
(98.5 \%)\end{array}$ & $\begin{array}{l}3734 \\
(97.7 \%)\end{array}$ & $\begin{array}{l}1202 \\
(98.0 \%)\end{array}$ & $0.02^{\star}$ \\
\hline $\begin{array}{l}\text { APOE-- } 4 \text { allele carrier } \\
\text { (Yes) }\end{array}$ & $\begin{array}{l}1981 \\
(26.4 \%)\end{array}$ & $\begin{array}{l}1658 \\
(25.4 \%)\end{array}$ & $\begin{array}{l}246 \\
(30.9 \%)\end{array}$ & $\begin{array}{l}77 \\
(43.0 \%)\end{array}$ & $<0.001^{*}$ & $\begin{array}{l}826 \\
(25.9 \%)\end{array}$ & $\begin{array}{l}901 \\
(27.0 \%)\end{array}$ & $\begin{array}{l}254 \\
(26.0 \%)\end{array}$ & 0.57 \\
\hline $\begin{array}{l}\text { Copies of rs } 16969968[\mathrm{~A}] \\
\text { allele }\end{array}$ & & & & & 0.65 & & & & 0.65 \\
\hline 0 & $\begin{array}{l}3084 \\
(43.8 \%)\end{array}$ & $\begin{array}{l}2688 \\
(43.8 \%)\end{array}$ & $\begin{array}{l}325 \\
(43.4 \%)\end{array}$ & $\begin{array}{l}71 \\
(42.3 \%)\end{array}$ & & $\begin{array}{l}1298 \\
(43.5 \%)\end{array}$ & $\begin{array}{l}1371 \\
(43.8 \%)\end{array}$ & $\begin{array}{l}415 \\
(44.6 \%)\end{array}$ & \\
\hline 1 & $\begin{array}{l}3197 \\
(45.4 \%)\end{array}$ & $\begin{array}{l}2771 \\
(45.2 \%)\end{array}$ & $\begin{array}{l}351 \\
(46.9 \%)\end{array}$ & $\begin{array}{l}75 \\
(44.6 \%)\end{array}$ & & $\begin{array}{l}1343 \\
(45.0 \%)\end{array}$ & $\begin{array}{l}1436 \\
(45.8 \%)\end{array}$ & $\begin{array}{l}418 \\
(44.9 \%)\end{array}$ & \\
\hline 2 & $\begin{array}{l}767 \\
(10.9 \%)\end{array}$ & $\begin{array}{l}673 \\
(11.0 \%)\end{array}$ & $\begin{array}{l}72 \\
(9.63 \%)\end{array}$ & $\begin{array}{l}22 \\
(13.1 \%)\end{array}$ & & $\begin{array}{l}344 \\
(11.5 \%)\end{array}$ & $\begin{array}{l}326 \\
(10.4 \%)\end{array}$ & $\begin{array}{l}97 \\
(10.4 \%)\end{array}$ & \\
\hline \multicolumn{10}{|l|}{$\begin{array}{l}\text { Continuous Variables } \\
\text { [Mean (SD)] }\end{array}$} \\
\hline Age (yrs) & $\begin{array}{l}65.8 \\
(8.86)\end{array}$ & $\begin{array}{l}65.1 \\
(8.67)\end{array}$ & $\begin{array}{l}70.2 \\
(8.60)\end{array}$ & $\begin{array}{l}73.6 \\
(7.77)\end{array}$ & $<0.001^{*}$ & $\begin{array}{l}65.5 \\
(8.78)\end{array}$ & $\begin{array}{l}67.3 \\
(8.71)\end{array}$ & $\begin{array}{l}62.1 \\
(8.36)\end{array}$ & $<0.001^{*}$ \\
\hline School years (yrs) & $\begin{array}{l}13.4 \\
(2.44)\end{array}$ & $\begin{array}{l}13.7 \\
(2.30)\end{array}$ & $\begin{array}{l}11.9 \\
(2.65)\end{array}$ & $\begin{array}{l}11.6 \\
(3.18)\end{array}$ & $<0.001^{*}$ & $\begin{array}{l}13.8 \\
(2.40)\end{array}$ & $\begin{array}{l}13.4 \\
(2.48)\end{array}$ & $\begin{array}{l}12.6 \\
(2.23)\end{array}$ & $<0.001 *$ \\
\hline Body Mass Index $\left(\mathrm{kg} / \mathrm{m}^{2}\right)$ & $\begin{array}{l}28.4 \\
(5.89)\end{array}$ & $\begin{array}{l}28.5 \\
(5.83)\end{array}$ & $\begin{array}{l}28.1 \\
(6.32)\end{array}$ & $\begin{array}{l}26.1 \\
(5.53)\end{array}$ & $<0.001^{*}$ & $\begin{array}{l}28.4 \\
(5.87)\end{array}$ & $\begin{array}{l}28.8 \\
(5.91)\end{array}$ & $\begin{array}{l}26.9 \\
(5.65)\end{array}$ & $<0.001^{*}$ \\
\hline Activities of daily living & $\begin{array}{l}0.22 \\
(0.71)\end{array}$ & $\begin{array}{l}0.16 \\
(0.59)\end{array}$ & $\begin{array}{l}0.40 \\
(0.88)\end{array}$ & $\begin{array}{l}1.52 \\
(1.90)\end{array}$ & $<0.001^{\star}$ & $\begin{array}{l}0.17 \\
(0.64)\end{array}$ & $\begin{array}{l}0.24 \\
(0.75)\end{array}$ & $\begin{array}{l}0.28 \\
(0.78)\end{array}$ & $<0.001^{*}$ \\
\hline $\begin{array}{l}\text { Instrumental activities of } \\
\text { daily living }\end{array}$ & $\begin{array}{l}0.19 \\
(0.66)\end{array}$ & $\begin{array}{l}0.12 \\
(0.45)\end{array}$ & $\begin{array}{l}0.35 \\
(0.81)\end{array}$ & $\begin{array}{l}2.24 \\
(2.05)\end{array}$ & $<0.001^{*}$ & $\begin{array}{l}0.14 \\
(0.59)\end{array}$ & $\begin{array}{l}0.21 \\
(0.73)\end{array}$ & $\begin{array}{l}0.25 \\
(0.66)\end{array}$ & $<0.001^{\star}$ \\
\hline CESD score & $\begin{array}{l}1.22 \\
(1.87)\end{array}$ & $\begin{array}{l}1.14 \\
(1.81)\end{array}$ & $\begin{array}{l}1.75 \\
(2.13)\end{array}$ & $\begin{array}{l}2.50 \\
(2.29)\end{array}$ & $<0.001^{*}$ & $\begin{array}{l}1.07 \\
(1.71)\end{array}$ & $\begin{array}{l}1.16 \\
(1.81)\end{array}$ & $\begin{array}{l}1.88 \\
(2.34)\end{array}$ & $<0.001^{*}$ \\
\hline $\begin{array}{l}\text { Smoking polygenic risk } \\
\text { score }\end{array}$ & $\begin{array}{l}0.01 \\
(0.99)\end{array}$ & $\begin{array}{l}0.00 \\
(0.99)\end{array}$ & $\begin{array}{l}0.06 \\
(1.03)\end{array}$ & $\begin{array}{l}0.14 \\
(1.00)\end{array}$ & $0.03^{*}$ & $\begin{array}{l}-0.16 \\
(0.97)\end{array}$ & $\begin{array}{l}0.08 \\
(0.98)\end{array}$ & $\begin{array}{l}0.25 \\
(1.03)\end{array}$ & $<0.001^{\star}$ \\
\hline AD polygenic risk score & $\begin{array}{l}0.01 \\
(1.00)\end{array}$ & $\begin{array}{l}-0.01 \\
(1.00)\end{array}$ & $\begin{array}{l}0.14 \\
(1.03)\end{array}$ & $\begin{array}{l}0.02 \\
(1.04)\end{array}$ & $0.001^{*}$ & $\begin{array}{l}0.01 \\
(1.02)\end{array}$ & $\begin{array}{l}0.00 \\
(1.00)\end{array}$ & $\begin{array}{l}0.07 \\
(0.98)\end{array}$ & 0.17 \\
\hline
\end{tabular}


Notes:

[a] All the statistics including count, frequency, mean, SD, and P value were calculated based on non-missing data for each variable.

[b] The overall P value was calculated from chi-square test or analysis of variance for categorical or continuous variables as appropriate, interpreted as differences between groups.

Table 3. Associations between polygenic risk score for smoking and smoking status, Health and Retirement Study, Wave 2010, European ancestry sample $(n=8741)^{\text {a }}$

\begin{tabular}{|c|c|c|c|c|c|c|c|c|c|c|c|c|}
\hline & \multicolumn{4}{|c|}{ Impaired Cognition \& Normal Sample } & \multicolumn{4}{|c|}{ Dementia \& Normal Sample } & \multicolumn{4}{|c|}{ Overall Sample } \\
\hline & $\mathbf{N}$ & OR $(9$ & $\mathrm{Cl} \%)$ & $\begin{array}{l}\text { Improvement } \\
\mathrm{C}^{2 \mathrm{~b}}\end{array}$ & $\mathbf{N}$ & OR $(9$ & $\mathrm{Cl} \%)$ & $\begin{array}{l}\text { Improvement } \\
\mathrm{C}^{2}\end{array}$ & $\mathbf{N}$ & OR $(9$ & $\mathrm{Cl} \%)$ & $\begin{array}{l}\text { Improvement } \\
\mathrm{C}^{2}\end{array}$ \\
\hline \multicolumn{13}{|l|}{$\begin{array}{l}\text { Former } \\
\text { vs. Never }\end{array}$} \\
\hline Crude & 7345 & 1.28 & $\begin{array}{l}(1.22, \\
1.34)\end{array}$ & - & 6791 & 1.28 & $\begin{array}{l}(1.21, \\
1.34)^{\prime}\end{array}$ & - & 7514 & 1.29 & $\begin{array}{l}(1.23, \\
1.35)\end{array}$ & - \\
\hline Adjusted $^{c}$ & 7345 & 1.32 & $\begin{array}{l}(1.26, \\
1.39)\end{array}$ & 118.1 & 6791 & 1.32 & $\begin{array}{l}(1.25, \\
1.39)\end{array}$ & 109.2 & 7514 & 1.33 & $\begin{array}{l}(1.26, \\
1.39)\end{array}$ & 126.2 \\
\hline \multicolumn{13}{|l|}{$\begin{array}{l}\text { Current } \\
\text { vs. Never }\end{array}$} \\
\hline Crude & 4829 & 1.51 & $\begin{array}{l}(1.41, \\
1.62)\end{array}$ & - & 4436 & 1.52 & $\begin{array}{l}(1.41, \\
1.63)\end{array}$ & - & 4918 & 1.52 & $\begin{array}{l}(1.42, \\
1.63)\end{array}$ & - \\
\hline Adjusted & 4829 & 1.51 & $\begin{array}{l}(1.41, \\
1.63)\end{array}$ & 123.6 & 4436 & 1.61 & $\begin{array}{l}(1.40, \\
1.64)\end{array}$ & 107.0 & 4918 & 1.52 & $\begin{array}{l}(1.41, \\
1.63)\end{array}$ & 127.0 \\
\hline
\end{tabular}

Abbreviations: Cl, Confidence Interval; OR, Odds Ratio

Notes:

[a] All the values were based on results from standard logistic regression analyses in each sample, in which "never smoking" was used as the reference group.

[b] Calculated by $2^{\star}(\log$ likelihood of full model - log likelihood of reduced model). Statistics larger than 10 indicates a valid instrument in convention.

[c] Adjusted for age, sex, education and five ancestry-specific principal component sets.

Table 4. Associations between polygenic score for smoking and cognitive status, Health and Retirement Study, Wave 2010, European ancestry sample $(n=8741)^{a}$ 


\begin{tabular}{|c|c|c|c|c|c|c|c|c|c|c|c|c|}
\hline & \multicolumn{6}{|c|}{ Impaired Cognition vs. Normal } & \multicolumn{6}{|c|}{ Dementia vs. Normal } \\
\hline & \multicolumn{3}{|c|}{ Former vs. Never } & \multicolumn{3}{|c|}{ Current vs. Never } & \multicolumn{3}{|c|}{ Former vs. Never } & \multicolumn{3}{|c|}{ Current vs. Never } \\
\hline & $\mathbf{N}$ & \multicolumn{2}{|c|}{ OR (95 Cl\%) } & $\mathbf{N}$ & \multicolumn{2}{|c|}{ OR (95 Cl\%) } & $\mathbf{N}$ & \multicolumn{2}{|c|}{ OR (95 Cl\%) } & $\mathbf{N}$ & \multicolumn{2}{|c|}{ OR (95 Cl\%) } \\
\hline \multicolumn{13}{|c|}{$\begin{array}{l}\text { Total effect of smoking polygenic } \\
\text { score }\end{array}$} \\
\hline Crude & 7345 & 1.06 & $\begin{array}{l}(0.98, \\
1.14)\end{array}$ & 4829 & 1.05 & $\begin{array}{l}(0.95, \\
1.15)^{\prime}\end{array}$ & 6791 & 1.16 & $\begin{array}{l}(0.99, \\
1.36)\end{array}$ & 4436 & 1.02 & $\begin{array}{l}(0.83, \\
1.27)^{\prime}\end{array}$ \\
\hline Adjusted (demographic) ${ }^{\mathrm{b}}$ & 7345 & 1.02 & $\begin{array}{l}(0.93, \\
1.11)^{\prime}\end{array}$ & 4829 & 1.03 & $\begin{array}{l}(0.93, \\
1.14)^{\prime}\end{array}$ & 6791 & 1.11 & $\begin{array}{l}(0.94, \\
1.32)\end{array}$ & 4436 & 1.00 & $\begin{array}{l}(0.80, \\
1.26)^{\prime}\end{array}$ \\
\hline Adjusted (health status) ${ }^{c}$ & 7191 & 1.01 & $\begin{array}{l}(0.93, \\
1.11)^{\prime}\end{array}$ & 4723 & 1.02 & $\begin{array}{l}(0.91 \\
1.13)^{\prime}\end{array}$ & 6590 & 1.04 & $\begin{array}{l}(0.83, \\
1.31)\end{array}$ & 4326 & 0.97 & $\begin{array}{l}(0.73, \\
1.28)^{\prime}\end{array}$ \\
\hline Adjusted (AD genetics) ${ }^{d}$ & 5856 & 1.02 & $\begin{array}{l}(0.92, \\
1.12)\end{array}$ & 3772 & 1.03 & $\begin{array}{l}(0.91, \\
1.16)^{\prime}\end{array}$ & 5353 & 1.00 & $\begin{array}{l}(0.78, \\
1.29)\end{array}$ & 3440 & 0.96 & $\begin{array}{l}(0.69, \\
1.33)^{\prime}\end{array}$ \\
\hline \multicolumn{13}{|c|}{$\begin{array}{l}\text { Direct effect of smoking polygenic score (adjusting for smoking } \\
\text { status) }\end{array}$} \\
\hline Crude & 7345 & 1.04 & $\begin{array}{l}(0.96, \\
1.13)\end{array}$ & 4829 & 1.00 & $\begin{array}{l}(0.91 \\
1.10)^{\prime}\end{array}$ & 6791 & 1.13 & $\begin{array}{l}(0.97 \\
1.32)\end{array}$ & 4436 & 1.01 & $\begin{array}{l}(0.82, \\
1.25)^{\prime}\end{array}$ \\
\hline Adjusted (demographic) & 7345 & 1.02 & $\begin{array}{l}(0.93, \\
1.11)^{\prime}\end{array}$ & 4829 & 0.99 & $\begin{array}{l}(0.89 \\
1.10)\end{array}$ & 6791 & 1.11 & $\begin{array}{l}(0.93, \\
1.31)^{\prime}\end{array}$ & 4436 & 0.99 & $\begin{array}{l}(0.79 \\
1.25)^{\prime}\end{array}$ \\
\hline Adjusted (health status) & 7191 & 1.01 & $\begin{array}{l}(0.92, \\
1.11)\end{array}$ & 4723 & 0.99 & $\begin{array}{l}(0.89, \\
1.10)^{\prime}\end{array}$ & 6590 & 1.05 & $\begin{array}{l}(0.84, \\
1.33)\end{array}$ & 4326 & 0.98 & $\begin{array}{l}(0.73, \\
1.30)^{\prime}\end{array}$ \\
\hline Adjusted (AD genetics) & 5856 & 1.02 & $\begin{array}{l}(0.92, \\
1.12)\end{array}$ & 3772 & 1.00 & $\begin{array}{l}(0.88, \\
1.12)\end{array}$ & 5353 & 1.01 & $\begin{array}{l}(0.78, \\
1.30)\end{array}$ & 3440 & 0.97 & $\begin{array}{l}(0.70, \\
1.36)^{\prime}\end{array}$ \\
\hline
\end{tabular}

Abbreviations: AD, Alzheimer's disease; APOE, Apolipoprotein E; CESD, Center for Epidemiological Studies Depression; Cl, Confidence Interval; OR, Odds Ratio; PGS, polygenic risk score

\section{Notes:}

[a] All the values were based on results from multivariable logistic regression in each sample, in which "never smoking" and "normal cognitive status" were used as the reference groups.

[b] Adjusted for age, sex, years of education and five ancestry-specific principal component sets.

[c] Adjusted for ever drink alcohol, history of stroke, hypertension, diabetes, BMI, and CESD score in addition to variables in [b].

[d] Adjusted for APOE4 allele status and AD PGS in addition to variables in [c].

Table 5. Associations between smoking status and cognitive status, Health and Retirement Study, Wave 2010, European ancestry samplea 


\begin{tabular}{|c|c|c|c|c|c|c|c|c|c|c|c|c|}
\hline & \multicolumn{6}{|c|}{ Former vs. Never } & \multicolumn{6}{|c|}{ Current vs. Never } \\
\hline & \multirow[b]{2}{*}{$\mathbf{N}$} & \multicolumn{2}{|c|}{$\begin{array}{l}\text { Logistic } \\
\text { Regression }\end{array}$} & \multicolumn{2}{|c|}{$\begin{array}{l}\text { Wald- } \\
\text { type/ratio }\end{array}$} & \multirow[t]{2}{*}{$\begin{array}{l}P \text { for } \\
\text { heterogeneity }^{b}\end{array}$} & & \multicolumn{2}{|c|}{$\begin{array}{l}\text { Logistic } \\
\text { Regression }\end{array}$} & \multicolumn{2}{|c|}{$\begin{array}{l}\text { Wald- } \\
\text { type/ratio }\end{array}$} & \multirow[t]{2}{*}{$\begin{array}{l}P \text { for } \\
\text { heterogeneity }\end{array}$} \\
\hline & & OR $(9$ & $\% \mathrm{Cl})$ & OR ( & $\% \mathrm{Cl})$ & & $\mathbf{N}$ & OR $(9$ & $\% \mathrm{Cl})$ & OR ( & $\% \mathrm{Cl})$ & \\
\hline Crude & 7345 & 1.33 & $\begin{array}{l}(1.14 \\
1.55)\end{array}$ & 1.26 & $\begin{array}{l}(0.92, \\
1.73)\end{array}$ & 0.76 & 4829 & 1.77 & $\begin{array}{l}(1.44 \\
2.15)\end{array}$ & 1.12 & $\begin{array}{l}(0.89 \\
1.41)\end{array}$ & $0.003^{*}$ \\
\hline $\begin{array}{l}\text { Adjusted } \\
\text { (demographic) }^{c}\end{array}$ & 7345 & 0.98 & $\begin{array}{l}(0.83 \\
1.16)\end{array}$ & 1.06 & $\begin{array}{l}(0.78 \\
1.45)\end{array}$ & 0.63 & 4829 & 1.62 & $\begin{array}{l}(1.29 \\
2.02)\end{array}$ & 1.07 & $\begin{array}{l}(0.83 \\
1.37)\end{array}$ & $0.01 *$ \\
\hline $\begin{array}{l}\text { Adjusted (health } \\
\text { status) }^{d}\end{array}$ & 7191 & 1.02 & $\begin{array}{l}(0.86 \\
1.22)\end{array}$ & 1.05 & $\begin{array}{l}(0.76 \\
1.44)\end{array}$ & 0.88 & 4723 & 1.43 & $\begin{array}{l}(1.12, \\
1.81)\end{array}$ & 1.04 & $\begin{array}{l}(0.80 \\
1.35)\end{array}$ & 0.06 \\
\hline $\begin{array}{l}\text { Adjusted (AD } \\
\text { genetics) })^{\mathrm{e}}\end{array}$ & 5856 & 1.03 & $\begin{array}{l}(0.85 \\
1.25)\end{array}$ & 1.07 & $\begin{array}{l}(0.75 \\
1.52)\end{array}$ & 0.86 & 3772 & 1.44 & $\begin{array}{l}(1.11 \\
1.87)\end{array}$ & 1.07 & $\begin{array}{l}(0.80 \\
1.42)\end{array}$ & 0.10 \\
\hline \multicolumn{13}{|l|}{$\begin{array}{l}\text { Dementia vs. } \\
\text { Normal }\end{array}$} \\
\hline Crude & 6791 & 1.60 & $\begin{array}{l}(1.18 \\
2.20)\end{array}$ & 1.84 & $\begin{array}{l}(0.97 \\
3.48)\end{array}$ & 0.70 & 4436 & 1.19 & $\begin{array}{l}(0.73 \\
1.88)\end{array}$ & 1.06 & $\begin{array}{l}(0.64 \\
1.76)\end{array}$ & 0.74 \\
\hline $\begin{array}{l}\text { Adjusted } \\
\text { (demographic) }\end{array}$ & 6791 & 1.13 & $\begin{array}{l}(0.81 \\
1.58)\end{array}$ & 1.47 & $\begin{array}{l}(0.80 \\
2.69)\end{array}$ & 0.45 & 4436 & 1.13 & $\begin{array}{l}(0.66 \\
1.87)\end{array}$ & 1.01 & $\begin{array}{l}(0.58 \\
1.75)\end{array}$ & 0.76 \\
\hline $\begin{array}{l}\text { Adjusted (health } \\
\text { status) }\end{array}$ & 6590 & 0.90 & $\begin{array}{l}(0.57 \\
1.42)\end{array}$ & 1.16 & $\begin{array}{l}(0.51 \\
2.64)\end{array}$ & 0.59 & 4326 & 0.90 & $\begin{array}{l}(0.46 \\
1.70)\end{array}$ & 0.92 & $\begin{array}{l}(0.47 \\
1.81)\end{array}$ & 0.94 \\
\hline $\begin{array}{l}\text { Adjusted (AD } \\
\text { genetics) }\end{array}$ & 5353 & 0.94 & $\begin{array}{l}(0.57 \\
1.55)\end{array}$ & 1.01 & $\begin{array}{l}(0.41 \\
2.52)\end{array}$ & 0.90 & 3440 & 0.82 & $\begin{array}{l}(0.37 \\
1.70)\end{array}$ & 0.90 & $\begin{array}{l}(0.41 \\
1.98)\end{array}$ & 0.84 \\
\hline
\end{tabular}

Abbreviations: CESD, Center for Epidemiological Studies Depression; Cl, Confidence Interval; MR, Mendelian Randomization; OR, Odds Ratio; AD, Alzheimer's disease

Notes:

[a] All values were based on results from multivariable logistic regression or Mendelian randomization analyses in each sample, in which "normal cognitive status" and "never smoking" were used as the reference groups.

[b] P value represents the statistical significance of the test of heterogeneity between logistic regression and Mendelian randomization.

[c] Adjusted for age, sex, years of education, and five ancestry-specific principal component sets.

[d] Adjusted for ever drink alcohol, history of stroke, hypertension, diabetes, BMI, and CESD score in addition to variables in [c].

[e] Adjusted for APOE4 allele status and AD PGS in addition to variables in [d].

\section{Figures}




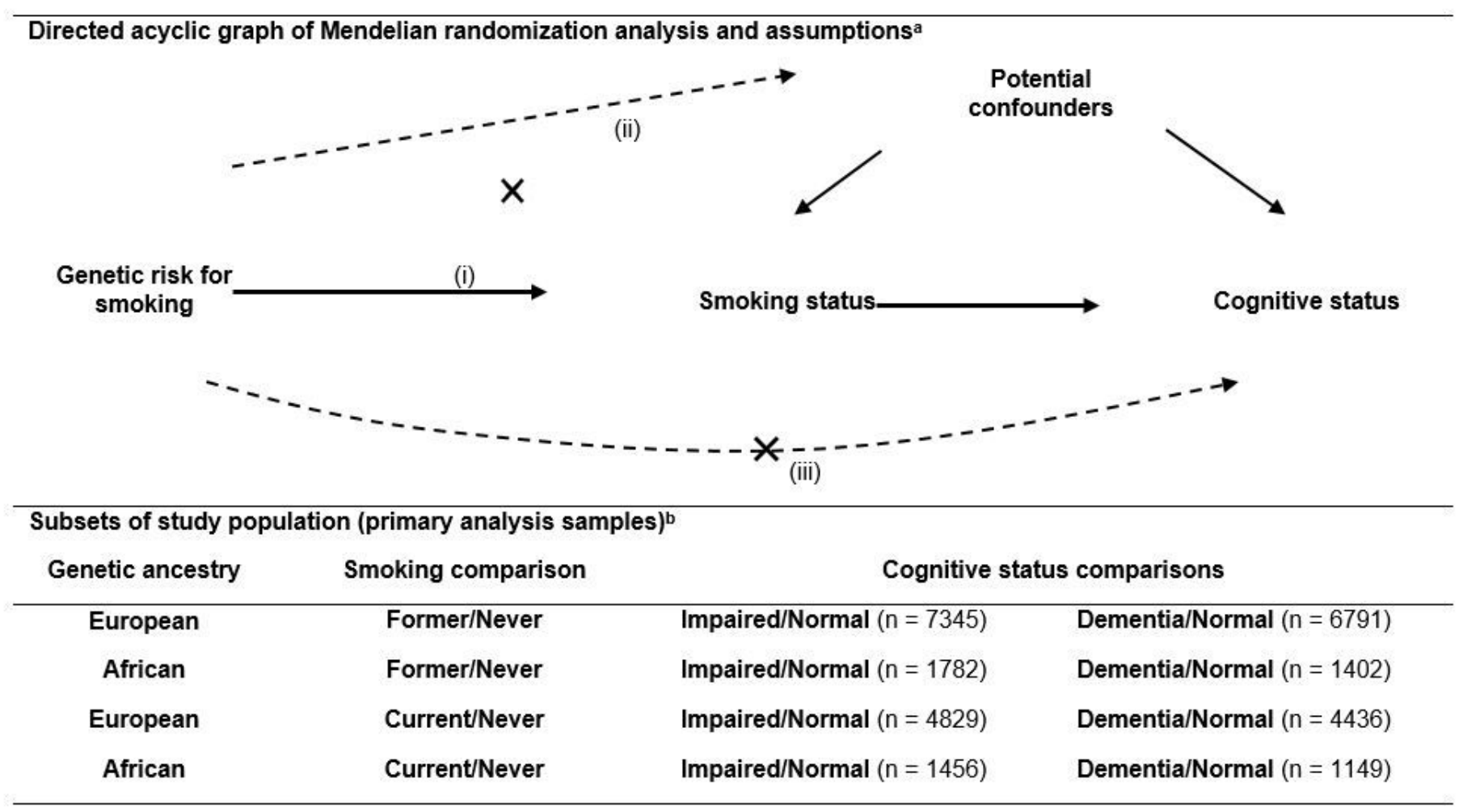

Figure 1

Mendelian randomization analyses structure and subsets of study population, Health and Retirement Study, Wave 2010 ( $\mathrm{n}=11242$ )a Notes: [a] Mendelian randomization assumptions: (i) the genetic variant must be associated with the exposure, (ii) the genetic variant must not be associated with any confounder of the exposure-outcome association and (iii) the genetic variant must be associated with the outcome only via the exposure. [b] Subsets used in standard logistic regression and Mendelian randomization analyses. All primary models adjusted for age, sex, years of education, and five ancestry-specific genetic principal components.

\section{Supplementary Files}

This is a list of supplementary files associated with this preprint. Click to download.

- SmokingMRSupmzfu.docx 